\title{
EDITORIAL
}

\section{NONPHARMACOLOGICAL TREATMENT OF COGNITIVE IMPAIRMENT}

\author{
J.E. MORLEY ${ }^{1}$, M. BERG-WEGER ${ }^{1,2}$, J. LUNDY ${ }^{3}$
}

1. Division of Geriatric Medicine, Saint Louis University School of Medicine, St. Louis, Missouri, USA; 2. School of Social Work, Saint Louis University, St. Louis Missouri, USA;

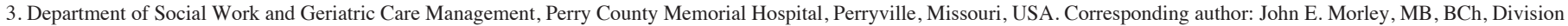
of Geriatric Medicine, Saint Louis University School of Medicine, 1402 S. Grand Blvd., M238, St. Louis, MO 63104, Email: john.morley@health.slu.edu

"Memory is a passion no less powerful or pervasive than love"

$\sim$ Ellie Wiesel

All Rivers Run to the Sea

Drugs available to treat dementia produce small improvements in cognition, but the clinical significance of these effects are questionable (1-3). In addition, they produce a variety of side effects including anorexia, weight loss, diarrhea, nausea, abdominal pain, dizziness, bradycardia, syncope and weakness. Thus, while dementia has traditionally been conceptualized from a medical model (4), it has become clear that dementia prognosis is strongly related to the environment and interpersonal relationships (5). Kitwood (5) identified 6 central needs for a person with dementia, viz., love, comfort, attachment, inclusion, occupation and identity. This has led to a variety of lifestyle and non-pharmacological interventions to manage cognitive impairment and behavioral and psychological symptoms of dementia (BPSD) (Table 1) (6).

\section{Table 1}

Lifestyle and nonpharmacological strategies to treat dementia

\begin{tabular}{ll}
\hline Cognition & $\begin{array}{l}\text { Behavioral and Psychological } \\
\text { Symptoms }\end{array}$ \\
\hline Lifestyle: & Music Therapy \\
Exercise & Behavioral Management Therapies \\
Mediterranean Diet & Caregiver Based Interventions \\
Extra Virgin Olive Oil & Staff Training in Communication Skills \\
Socialization & Person Centered Care \\
Prevent Cardiovascular Disease & Environment-based Intervention \\
Computer Games & Animal Assisted/Robotic Therapy \\
& Exercise \\
Behavioral: & Snoezelen Room \\
Montessori Activities for Seniors & Namaste Room \\
SAIDO & STAR (Staff Training in Assisted Living \\
Reminiscence Therapy & Residences) \\
Reality Orientation & \\
Cognitive Retention Therapy & \\
Cognitive Stimulation Therapy & \\
\hline
\end{tabular}

\section{Lifestyle Interventions}

A recent meta-analysis found that exercise therapy improved cognition with aerobic exercise performing better than resistance exercise (7). Other meta-analyses have failed to find similar effects, though this outcome is supported by animal studies.

There is strong epidemiological evidence that a Mediterranean diet enhances cognition and slows the development of dementia (8-10). In an animal model of Alzheimer's disease, the SAMP8, extra virgin olive oil decreased oxidative damage and reversed memory problems (11). Other polyphenol containing foods also reverse memory problems $(12,13)$. The PREDIMED study showed that extra virgin olive oil, and, to a lesser extent, mixed nuts, improved cognition $(14,15)$. The MIND diet (a combination of a Mediterranean and the DASH diet) lowered the risk of dementia by $54 \%$ (16). While fish oils improve memory in the SAMP8 mice (17), the available data in humans has failed to show memory improvement $(18,19)$.

The FINGER study was a multidomain intervention in older persons with high cardiovascular risk factors utilizing a Mediterranean diet, exercise, cognitive training and treatment of vascular risk factors (20). The study was conducted over 2 years. It showed a statistically significant improvement in a comprehensive neuropsychological test battery in the intervention group. This is in keeping with the recent decline in dementia in the United States, suggesting that cardiovascular disease prevention decreases the development of dementia (21). Based on postmortem studies at least $33 \%$ of dementia is due to vascular lesions (22).

\section{Cognition Therapy for Dementia}

The Cochrane Reviews found that reminiscence therapy had a small improvement in cognition and in quality of life (23). A particularly enjoyable form of reminiscence therapy has been sports reminiscence, such as football in Scotland (24) and baseball in St. Louis (25).

Cognitive Stimulation Therapy (CST) is an evidencebased, structured group intervention that was developed at the University College of London (www.cstdementia.com). It has 18 key principles and a set of manuals to allow it to be reproduced with high fidelity. It is conducted twice a week for seven weeks and can be followed by Maintenance CST for up Published online April 30, 2018, http://dx.doi.org/10.1007/s12603-018-1036-2 


\section{THE JOURNAL OF NUTRITION, HEALTH \& AGINGC}

to one year. The original CST trial was carried out in 23 centers and showed significant improvement in Mini Mental Status Examination (MMSE), Alzheimer's Disease Assessment Scale (ADAS), and quality of life (26). The number needed to treat to improve cognition was 6 . Recently, a metanalysis found that cognitive stimulation significantly improved scores on MMSE, ADAS-Cognitive Subscale and Quality of Life (27). It is more cost-effective than donepezil (28). It is seen by participants as being emotionally positive and that it produces changes in everyday life (29). Maintenance CST appears to maintain the cognitive improvement (30). The National Institute for Health and Clinical Excellence (NICE) has stated that "People with mild/moderate dementia of all types should be given the opportunity to participate in a structured group cognitive stimulation program.........irrespective of any anti-dementia drug received..." It has been demonstrated that it can be introduced into non-academic community settings with positive outcomes $(31,32)$.

SAIDO, a Japanese version of CST, has been demonstrated to successfully improve cognition in Japan (33).

\section{Conclusion}

Available data confirms that lifestyle and cognitive therapies can improve memory at least as well as drug therapy $(34,35)$. There is a need for controlled community-based studies to demonstrate that it can be successfully instituted in a variety of community settings with reasonable fidelity. While not reviewed in this editorial it is clear that nonpharmacological interventions of a variety of types work (including repetitive transcranial magnetic stimulation) much better than antipsychotic drugs (36-40).

\section{References}

1. Strohle A, Schmidt DK, Schultz F, et al. Drug and exercise treatment of Alzheimer disease and mild cognitive impairment: A systematic review and meta-analysis of effects on cognition in randomized controlled trials. Am J Geriatr Psychiatry 2015;23:1234-1249.

2. Muayqil T, Camicioli R. Systematic review and meta-analysis of combination therapy with cholinesterase inhibitors and memantine in Alzheimer's disease and other dementias. Dement Geriatr Cogn Dis Extra 2012;2:546-572.

3. Raina P, Santaguida P, Ismaila A, et al. Effectiveness of cholinesterase inhibitors an memantine for treating dementia: Evidence review for a clinical practice guideline. Ann Intern Med 2008;148:379-397.

4. Lyman KA. Bringing the social back in: A critique of the biomedicalization of dementia. Gerontologist 1989;29:597-605.

5. Kitwood T. Toward a theory of dementia care: Ethics and interaction. J Clin Ethocs 1998;9:23-34.

6. Abraha I, Rimland JM, Trotta FM, et al. Systematic review of systematic reviews of non-pharacological interventions to treat behavioural disturbances in older patients with dementia. The SENOR-OnTop series. BMJ Open 2017;7:e012759.

7. Panza GA, Taylor BA, MacDonald HV, et al. Can exercise improve cognitive symptoms of Alzheimer's disease? J Am Geriatr Soc 2018;66:487-495.

8. Anastasiou CA, Yannakoulia M, Kosmidis MH, et al. Mediterranean diet and cognitive health: Initial results from the Hellenic longitudinal investigation of ageing and diet. PLoS One. 2017;12(8):e0182048.

9. Aridi YS, Walker JL, Wright ORL. The association between the Mediterranean dietary pattern and cognitive health: A systematic review. Nutrients 2017;9(7). Doi: 10.3390/nu9070674.

10. Singh B, Parsaik AK, Mielke MM, et al. Association of Mediterranean diet with mild cognitive impairment and Alzheimer's disease: A systematic review and metaanalysis. J Alzheimers Dis 2014;39:271-282.

11. Farr SA, Price TO, Dominguez LJ, et al. Extra virgin olive oil improves learning and memory in SAMP8 mice. J Alzheimers Dis 2012:28;81-92.

12. Farr SA, Niehoff ML, Ceddia MA, et al. Effect of botanical extracts containing carnosic acid or rosmarinic acid on learning and memory in SAMP8 mice. Physiol Behav 2016;165:328-338

13. Dal-Pan A, Dudonne S, Bourassa P, et al. Cognitive-enhancing effects of a polyphenols-rich extract from fruits without changes in neuropathology in an animal model of Alzheimer's disease. J Alzheimers Dis 2017;55:115-135.

14. Martinez-Lapiscina EH, Clavero P, Toledo E, et al. Virgin olive oil supplementation and long-term cognition: The PREDIMED-NAVARRA randomized trial. J Nut Health Aging 2013;17:544-552.

15. Abbatecola AM, Russo M, Barbieri M. Dietary patterns and cognition in older persons. Curr Opi Clin Nutr Metab Care 2018;21:10-13.

16. Morris MC, Tangney CC, Wang Y, et al. MIND diet associated with reduced incidence of Alzheimer's disease. Alzheimers Dement 2015;11:1007-1014.

17. Petursdottir AL, Farr SA, Morley JE, et al. Effect of dietary n-3 polyunsaturated fatty acids on brain lipid fatty acid composition, learning ability, and memory of senescence-accelerated mouse. J Gerontol A Biol Sci Med Sci 2008;63:1153-1160.

18. Cederholm T, Palmblad J. Are omega-3 fatty acids options for prevention and treatment of cognitive decline and dementia? Curr Opin Clin Nutr Metab Care 2010;13:150-155.

19. Andrieu S, Guyonnet S, Coley N, et al. Effect of long-term omega 3 polyunsaturated fatty acid supplementation with or without multidomain intervention on cognitive function I elderly adults with memory complaints (MAPT): A randomised, placebocontrolled trial. Lancet Neurol 2017;16:377-389.

20. Ngandu T, Lehtisalo J, Solomon A, et al. A 2 year multidomain intervention of diet, exercise, cognitive training, a vascular risk monitoring versus control to preven cognitive decline in at-risk elderly people (FINGER): A randomized controlled trial. Lancet 2015:385-:2255-2263.

21. Langa KM, Larson EB, Crimmins EM, et al. A comparison of the prevalence of dementia in the United States in 2000 and 2012. JAMA Intern Med 2017:177:51-58.

22. Sonnen JA, Larson EB, Crane PK, et al. Pathological correlates of dementia in a longitudinal, population-based sample of aging. Ann Neurol 2007:62:406-413.

23. Woods B, O'Philbin L, Farrell EM, et al. Reminiscence therapy for dementia. Cochrane Database Syst Rev 2018 Mar 1;3:CD001120.

24. Coll-Planas L, Watchman K, Domenech S, et al. Developing evidence for footbal (soccer) reminiscence interventions within long-term care: A co-operative approach applied in Scotland and Spain. J Am Med Dir Assoc 2017;18:355-360.

25. Wingbermuehle C, Bryer D, Berg-Weger, et al. Baseball reminiscence league: A model for supporting persons with dementia. J Am Med Dir Assoc 2014;15:85-9.

26. Spector A, Thorgrimsen L, Woods B, et al. Efficacy of an evidence-based cognitive stimulation therapy programme for people with dementia: randomised controlled trial. Br J psychiatry 2003;183:248-254

27. Kim K, Han JW, So Y, et al. Cognitive stimulation as a therapeutic modality for dementia: A meta-analysis. Psychiatry Investig 2017;14:626-639.

28. Knapp M, Thorgrimsen L, Patel A, et al. Cognitive stimulation therapy for people with dementia: Cost-effectiveness analysis. Br J Psychiatry 2006;188:574-580

29. Spector A, Gardner C, Orrell M. The impact of cognitive stimulation therapy groups on people with dementia: Views from participants, their carers and group facilitators. Aging Ment Health 2011;15:945-949.

30. Orrell M, Aguirre E, Spector A, et al. Maintenance cognitive stimulation therapy for dementia: Single-blind, multicenter, pragmatic randomized controlled trial. Br J Psychiatry 2014;204:454-461.

31. Berg-Weger M, Tebb S, Henderson-Kalb J, et al. Cognitive stimulation therapy: A tool for your practice with persons with dementia? J Am Med Dir Assoc 2015;16:795-796.

32. Loraine J, Taylor S, McAllister M. Cognitive and physical stimulation therapy. J Am Med Dir Assoc 2014:15:140-141.

33. Kawashima R, Hiller DL, Sereda SL, et al. SAIDO learning as a cognitive intervention for dementia care: A preliminary study. J Am Med Dir Assoc 2015; 16:56-62.

34. Morley JE, Morris JC, Berg-Weger M, et al. Brain health: The importance of recognizing cognitive impairment: An IAGG consensus conference. J Am Med Dir Assoc 2015;16:731-739.

35. Morley JE, Cruz-Oliver DM. Cognitive stimulation therapy. J Am Med Dir Assoc 2014; 15:689-691.

36. Volicer L. Toward better terminology of behavioral symptoms of dementia. J Am Med Dir Assoc 2012;13:3-4.

37. Tolson D, Rolland Y, Andrieu S, et al. International Association of Gerontology and Geriatrics: A global agenda for clinical research and quality of care in nursing homes. J Am Med Dir Assoc 2011;12:184-189.

38. Morley JE. New horizons in the management of Alzheimer's disease. J Am Med Dir Assoc 2015;16:1-5.

39. Morley JE, Farr SA. Alzheimer mythology: A time to think out of the box. J Am Med Dir Assoc 2016;17:769-774.

40. Antczak J, Kowalska K, Klimkowicz-Mrowiec A, et al. Repetitive transcrania magnetic stimulation for the treatment of cognitive impairment in frontotemporal dementia: An open-label pilot study. Neuropsychiatr Dis Treat 2018;14:749-755. 